\title{
Two Families of Sliding Mode Controllers for a Doubly-Fed Induction Generator in an Isolated Generation System
}

\author{
R. Galindo \\ Centro Nacional de \\ Investigación y Desarrollo \\ Tecnológico, Interior \\ Internado Palmira s/n, Col. \\ Palmira. Cuernavaca, \\ Morelos, 62490, México. \\ robertogalindo@cenidet.edu.mx \\ (This work has been financed by CONACYT \\ through the scholarship No. 130885)
}

\author{
M. Cotorogea \\ Centro Nacional de \\ Investigación y Desarrollo \\ Tecnológico, Interior \\ Internado Palmira $s / n$, Col. \\ Palmira. Cuernavaca, \\ Morelos, 62490, México. \\ pemcp@cenidet.edu.mx
}

\author{
D. Biel \\ Dpt. d'enginyeria \\ Electrónica. E.U.P.V.G., \\ Universidad Politécnica de \\ Cataluña (UPC), c/ Víctor \\ Balaguer s/n 08800- \\ Vilanova i la Geltrú \\ (Barcelona), España. \\ biel@eel.upc.es
}

\begin{abstract}
In this paper the authors consider the Sliding Mode Control (SMC) of a Doubly Fed Induction Generator (DFIG), supplying an isolated RL load in a Variable Speed-Constant Frequency (VSCF) generation system. It must be reminded that in electric machines the existence of parameter changes, caused by several reasons like winding temperature variation, hysteresis and saturation, is well recognized, but rarely accounted for. For this reason, SMC has been considered. SMC has various attractive features like order reduction, robustness, disturbance rejection, and, sometimes, simple implementation. In this paper, some ideas of SMC applied by Utkin et. al. for controlling the speed or torque of a squirrel-cage induction motor are used to design two families of controllers for regulating amplitude and frequency of the voltage generated by a DFIG. First simulation results are presented as well.
\end{abstract}

\section{Introduction}

Since the second half of the 1980's, it has been devoted a higher research effort focused on Wind Energy Conversion Systems (WECSs), because of the increasingly world interest for achieving a sustainable development by using renewable energies. Because of the wind nature, in order to generate constant frequency voltages, constant-speed-WECSs were firstly proposed. However, variable speed WECS operation can be considered advantageous, because additional energy can be collected when wind speed increases.
Variable speed WECSs must use an electronic power converter, so they can be classified in full power handling WECS (also called direct-in-line) and partial power handling WECS, considering both the converter placement and ratings. In a full power handling WECS, the power converter is in series with the induction or synchronous generator, in order to transform the variable amplitude/frequency produced voltages into constant amplitude/frequency voltages, and it must be able to process all the generated power. In a partial power handling WECS, the converter to control the electric machine is in a secondary generator circuit, and it only processes a portion of the total generated power (e.g. slip power), which constitutes an advantage in terms of reduced cost of the converter and increased efficiency of the system [1]. This paper is focused on a partial power handling stand-alone WECS based on a Doubly-Fed Induction Generator (DFIG).

Variable speed WECSs supplying an isolated load have already been considered by other researchers. In [2], a stator voltage direct control is proposed using PI regulators. It offers a good dynamic performance, but is load dependent, which causes some practical difficulties. In [3], a system, where the rotor is fed from a battery through a PWM current source inverter, is presented. Additionally, regulation of the rms generated voltages is proposed, which results in considerable voltage errors and load dependency. In [4]-[6], several PI-based indirect stator voltage vector control approaches are presented for a WECS in which a back-to-back (B2B) converter is used to manage the power interchange between the stator and rotor circuits. The proposed control strategies produce good dynamic performance without any load dependency. 
However, DFIG parameter changes might degrade the control performance.

In order to take advantage of the robustness and disturbance rejection features of the SMC, in this paper two families of stator voltage sliding-mode controllers are proposed. To present the work, this paper is organized as follows. In Section 2, the considered system and its model are described. In Section 3, the controllers design is explained. In Section 4, preliminary simulation results are presented. Finally, in Section 5, the conclusions are given and some future activities are listed.

\section{System description}

The considered WECS is depicted in Figure 1. In this system, energy is collected by a wind turbine (WT) and transferred to a DFIG by a rotational movement through a drive train (DT). The DT increases the rotational speed using a gear box (GB). The DFIG transforms the received mechanical energy into electrical one in order to supply an isolated load (both main and auxiliary). The system operation is controlled by a B2B converter. At this first stage, only a main RL load has been considered and the WT has been substituted by a speed-controlled $\mathrm{dc}$ motor. Afterwards, the auxiliary load and the WT will be taken into account.

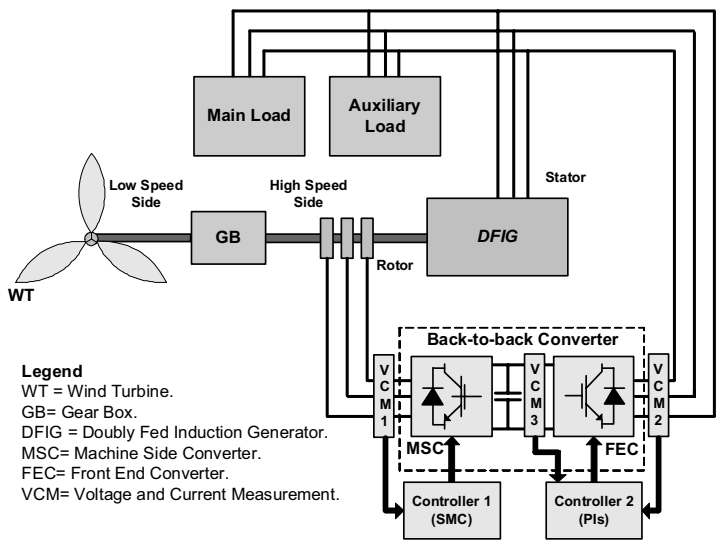

Figure 1. Wind Energy Conversion System (WECS) to supply an isolated load.

In the WECS, the front end converter (FEC) manages the power flow between rotor and stator circuits by a cascaded control system, in which the inner loop controls the converter currents and the outer one regulates the dc-link voltage, similar to the approach in [4]-[5]. This paper presents the design of a SMC controller that uses the machine side converter (MSC) for regulating the stator voltage generated by the DFIG.
Figure 2 shows the electric subsystem of the considered WECS. The converters forming the B2B are taken as three-phase voltage sources.

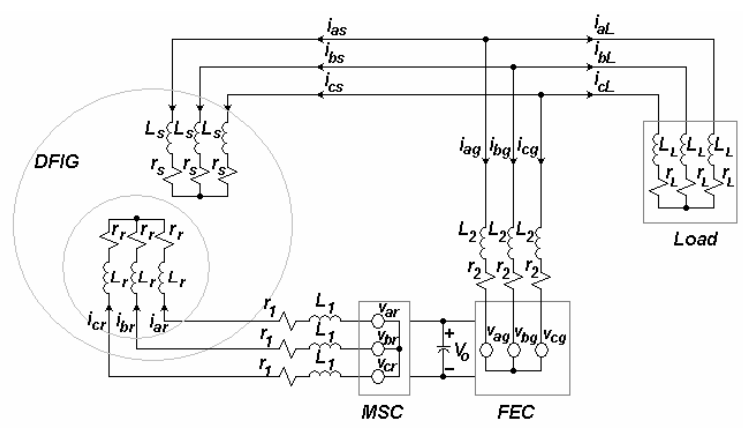

Figure 2. Electric subsystem of the considered WECS.

Applying Kirchhoff voltage and current laws, KVL and KCL, respectively, to the circuit shown in Figure 2, and considering the three-phase DFIG model derived in [7], following matrix equation results:

$$
\begin{aligned}
& \frac{d\left(\mathbf{i}_{a b c}\right)}{d t}=\mathbf{A}_{a b c} \mathbf{i}_{a b c}+\mathbf{B}_{a b c} \mathbf{v}_{a b c} \\
& \mathbf{i}_{L}=-\mathbf{i}_{s}-\mathbf{i}_{g} \\
& \mathbf{v}_{L}=\mathbf{v}_{s}=r_{s} \cdot \mathbf{i}_{s}+d\left(\boldsymbol{\lambda}_{a b c s}\right) / d t
\end{aligned}
$$

where:

$$
\begin{aligned}
& \mathbf{A}_{a b c}=\mathbf{L}^{-1} \cdot\left[\begin{array}{ccc}
r_{s} \mathbf{I}_{3} & d\left(\mathbf{L}_{s r}\right) / d t & -r_{2} \mathbf{I}_{3} \\
d\left(\mathbf{L}_{s r}\right)^{T} / d t & \left(r_{r}+r_{1}\right) \mathbf{I}_{3} & \mathbf{0}_{3} \\
-r_{L} \mathbf{I}_{3} & \mathbf{0}_{3} & -\left(r_{2}+r_{L}\right) \mathbf{I}_{3}
\end{array}\right] \\
& \mathbf{B}_{a b c}=\mathbf{L}^{-1} \\
& \mathbf{L}=\left[\begin{array}{ccc}
\mathbf{L}_{s} & \mathbf{L}_{s r} & -L_{2} \mathbf{I}_{3} \\
\left(\mathbf{L}_{s r}\right)^{T} & \left(\mathbf{L}_{r}+L_{1} \mathbf{I}_{3}\right) & \mathbf{0}_{3} \\
-L_{L} \mathbf{I}_{3} & \mathbf{0}_{3} & -\left(L_{2}+L_{L}\right) \mathbf{I}_{3}
\end{array}\right] \\
& \mathbf{L}_{s}=\left[\begin{array}{ccc}
L_{l s}+L_{m s} & -\frac{1}{2} L_{m s} & -\frac{1}{2} L_{m s} \\
-\frac{1}{2} L_{m s} & L_{l s}+L_{m s} & -\frac{1}{2} L_{m s} \\
-\frac{1}{2} L_{m s} & -\frac{1}{2} L_{m s} & L_{l s}+L_{m s}
\end{array}\right] \\
& \mathbf{L}_{r}=\left[\begin{array}{ccc}
L_{l r}+L_{m r} & -\frac{1}{2} L_{m r} & -\frac{1}{2} L_{m r} \\
-\frac{1}{2} L_{m r} & L_{l r}+L_{m r} & -\frac{1}{2} L_{m r} \\
-\frac{1}{2} L_{m r} & -\frac{1}{2} L_{m r} & L_{l r}+L_{m r}
\end{array}\right] \\
& \mathbf{L}_{s r}=L_{s r} \cdot\left[\begin{array}{ccc}
\cos \theta_{r} & \cos \left(\theta_{r}+\gamma\right) & \cos \left(\theta_{r}-\gamma\right) \\
\cos \left(\theta_{r}-\gamma\right) & \cos \theta_{r} & \cos \left(\theta_{r}+\gamma\right) \\
\cos \left(\theta_{r}+\gamma\right) & \cos \left(\theta_{r}-\gamma\right) & \cos \theta_{r}
\end{array}\right] \\
& \mathbf{i}_{a b c}=\left[\begin{array}{lll}
\mathbf{i}_{s}^{T} & \mathbf{i}_{r}^{T} & \mathbf{i}_{g}^{T}
\end{array}\right]^{T}
\end{aligned}
$$




$$
\begin{aligned}
& \mathbf{i}_{\bullet}^{T}=\mathbf{i}_{a b c \bullet}^{T}=\left[\begin{array}{lll}
i_{a \bullet} & i_{b \bullet} & i_{c} \cdot
\end{array}\right] \\
& \mathbf{v}_{a b c}=\left[\begin{array}{lll}
\mathbf{v}_{g}^{T} & \mathbf{v}_{r}^{T} & \mathbf{v}_{g}^{T}
\end{array}\right]^{T} \\
& \mathbf{v}_{\bullet}^{T}=\mathbf{v}_{a b c \bullet}^{T}=\left[\begin{array}{lll}
v_{a \bullet} & v_{b \bullet} & v_{c \bullet}
\end{array}\right] \\
& \gamma=2 \pi / 3
\end{aligned}
$$

where: $r_{s}$ and $r_{r}$ are the stator and rotor winding resistances [ $\Omega$ ], $L_{l s}$ and $L_{l r}$ are leakage inductances corresponding to a stator or rotor winding $[\mathrm{H}]$, $L_{m s}$ and $L_{m r}$ are mutual inductances between two stator or rotor windings $[\mathrm{H}], L_{s r} \cos \alpha$, with: $\alpha=\theta_{r}, \theta_{r}+\gamma$ or $\theta_{r}-\gamma$, are mutual inductances between a stator winding and a rotor winding $[\mathrm{H}]$, $\theta_{r}=\frac{P}{2} \theta_{m}$ is the angular position of the axes associated with rotor electromagnetic fields [rad], $\theta_{m}$ is the mechanical angular position of the rotor shaft [rad] and $P$ is the DFIG pole number.

The model of the B2B is based in [8] and [9]. In this model, the output voltage of each converter depends on the gate signals or pulses $g$ and on the dclink voltage $V_{0}$. So, the next relations are valid:

$$
\begin{aligned}
& \mathbf{v}_{a b c \bullet}=\mathbf{A}_{a b c}^{123} \cdot \mathbf{v}_{123 \bullet} \\
& \mathbf{v}_{a b c \bullet}=\left[\begin{array}{lll}
v_{a \bullet} & v_{b \bullet} & v_{c \bullet}
\end{array}\right]^{T} \\
& \mathbf{v}_{123 \bullet}=\left[\begin{array}{lll}
v_{1} & v_{2} & v_{3 \bullet}
\end{array}\right]^{T} \\
& \mathbf{A}_{a b c}^{123}=\frac{1}{3}\left[\begin{array}{ccc}
2 & -1 & -1 \\
-1 & 2 & -1 \\
-1 & -1 & 2
\end{array}\right] \\
& v_{j \bullet}=\left(2 g_{\bullet j}-1\right) \frac{V_{o}}{2} \\
& g_{\bullet(j+3)}=1-g_{\bullet j}, \text { and } j=1,2,3
\end{aligned}
$$

where: $\bullet=r$ for the MSC and $\bullet=g$ for the FEC; $v_{i \bullet}$ is an output phase voltage, with $i=a, b, c$; $g_{\bullet j}=0,1$ is the gate signal applied to the $j$-th switch and $V_{o}$ is the dc-link voltage.

To determine the dc-link voltage, KCL is applied to the upper bus node and yields:

$$
-i_{o 1}+i_{o 2}-I_{0}=0
$$

where: $I_{0}$ is the current feeding the dc-link capacitor, $i_{o 2}=g_{g 1} i_{a g}+g_{g 2} i_{b g}+g_{g 3} i_{c g}$ is the FEC "output" current and $i_{o 1}=g_{r 1} i_{a r}+g_{r 2} i_{b r}+g_{r 3} i_{c r}$ is the MSC "input" current.
Accordingly, the dc-link capacitor voltage will be given by:

$$
\frac{d V_{o}}{d t}=\frac{1}{C_{o}} I_{0}=\frac{1}{C_{o}}\left(i_{o 2}-i_{o 1}\right)
$$

To obtain a $d q$ WECS model to simplify the DFIG controller design, it is necessary to apply an $a b c$ to $d q$ transformation to the three-phase model in (1). This transformation is defined by the expressions in Table 1.

Table 1. Arbitrary Reference Frame Transformation [9]

\begin{tabular}{|c|}
\hline Direct transformation \\
\hline $\mathbf{f}_{\alpha \beta}=\mathbf{A}_{\alpha \beta}^{a b c} \cdot \mathbf{f}_{a b c}$ \\
$\mathbf{A}_{\alpha \beta}^{a b c}=\frac{2}{3}\left[\begin{array}{ccc}1 & -1 / 2 & -1 / 2 \\
0 & \sqrt{3} / 2 & -\sqrt{3} / 2\end{array}\right]$ \\
$\mathbf{f}_{d q}=\mathbf{A}_{d q}^{\alpha \beta} \cdot \mathbf{f}_{\alpha \beta}$ \\
$\mathbf{A}_{d q}^{\alpha \beta}=\left[\begin{array}{cc}\cos \phi & \operatorname{sen} \phi \\
-\operatorname{sen} \phi & \cos \phi\end{array}\right]$ \\
\hline Inverse transformation \\
\hline $\mathbf{f}_{a b c}=\left(\mathbf{A}_{\alpha \beta}^{a b c}\right)^{+} \cdot \mathbf{f}_{\alpha \beta}=\mathbf{A}_{a b c}^{\alpha \beta} \cdot \mathbf{f}_{\alpha \beta}$ \\
$\mathbf{A}_{a b c}^{\alpha \beta}=\left(\mathbf{A}_{\alpha \beta}^{a b c}\right)^{+}=\frac{3}{2}\left(\mathbf{A}_{\alpha \beta}^{a b c}\right)^{T}$ \\
\hline $\mathbf{f}_{\alpha \beta}=\left(\mathbf{A}_{d q}^{\alpha \beta}\right)^{-1} \cdot \mathbf{f}_{d q}=\mathbf{A}_{\alpha \beta}^{d q} \cdot \mathbf{f}_{d q}$ \\
$\mathbf{A}_{\alpha \beta}^{d q}=\left(\mathbf{A}_{d q}^{\alpha \beta}\right)^{-1}=\left(\mathbf{A}_{d q}^{\alpha \beta}\right)^{T}$ \\
\hline $\begin{array}{l}\text { where: } \phi=\theta \text { for stator variables and } \phi=\theta-\theta_{r} \text { for } \\
\text { rotor variables. Furthermore, } \theta \text { is the arbitrary } \\
\text { reference frame position [rad]. NOTE: Superscript }+ \\
\text { denotes the pseudo-inverse. }\end{array}$ \\
\hline
\end{tabular}

Applying the arbitrary reference frame transformation, given in Table 1, to the three-phase model in (1), the next $d q$ model is derived:

$$
\begin{aligned}
& \frac{d(\mathbf{i})}{d t}=\mathbf{A} \mathbf{i}+\mathbf{B}_{g} \mathbf{v}_{d q g}+\mathbf{B}_{r} \mathbf{v}_{d q r} \\
& \mathbf{i}_{d q L}=-\mathbf{i}_{d q s}-\mathbf{i}_{d q g} \\
& \mathbf{v}_{d q L}=\mathbf{v}_{d q s}=r_{s} \cdot \mathbf{i}_{d q s}+\omega \mathbf{J}_{2} \boldsymbol{\lambda}_{d q s}+d\left(\boldsymbol{\lambda}_{d q s}\right) / d t \\
& \boldsymbol{\lambda}_{d q s}=L_{s} \cdot \mathbf{i}_{d q s}+M \cdot \mathbf{i}_{d q r} \\
& \mathbf{A}=-\mathcal{L}^{-1}\left[\begin{array}{ll}
\mathbf{\Omega}(\omega) \mathcal{L}+\mathbf{R}
\end{array}\right] \\
& \mathbf{B}_{g}=\mathcal{L}^{-1} \cdot\left[\begin{array}{lll}
\mathbf{I}_{2} & \mathbf{0}_{2} & \mathbf{I}_{2}
\end{array}\right]^{T} \\
& \mathbf{B}_{r}=\mathcal{L}^{-1} \cdot\left[\begin{array}{lll}
\mathbf{0}_{2} & \mathbf{I}_{2} & \mathbf{0}_{2}
\end{array}\right]^{T}
\end{aligned}
$$




$$
\begin{aligned}
& \mathcal{L}=\left[\begin{array}{ccc}
L_{s} \mathbf{I}_{2} & M_{2} & -L_{2} \mathbf{I}_{2} \\
M_{2} & L_{r}^{*} \mathbf{I}_{2} & \mathbf{0}_{2} \\
-L_{L} \mathbf{I}_{2} & \mathbf{0}_{2} & -L_{2}
\end{array}\right] \\
& \mathbf{R}=\left[\begin{array}{ccc}
r_{s} \mathbf{I}_{2} & \mathbf{0}_{2} & -r_{2} \mathbf{I}_{2} \\
\mathbf{0}_{2} & r_{r}^{*} \mathbf{I}_{2} & \mathbf{0}_{2} \\
-r_{L} \mathbf{I}_{2} & \mathbf{0}_{2} & -r \mathbf{I}_{2}
\end{array}\right] \\
& \boldsymbol{\Omega}(\omega) \mathcal{L}=\left[\begin{array}{ccc}
\omega L_{s} \mathbf{J}_{2} & \omega M \mathbf{J}_{2} & -\omega L_{2} \mathbf{J}_{2} \\
\omega_{r e l} M \mathbf{J}_{2} & \omega_{r e l} L_{r}^{*} \mathbf{J}_{2} & \mathbf{0}_{2} \\
-\omega L_{L} \mathbf{J}_{2} & \mathbf{0}_{2} & -\omega\left(L_{2}+L_{L}\right) \mathbf{J}_{2}
\end{array}\right] \\
& \mathbf{i}^{T}=\left[\begin{array}{lll}
\mathbf{i}_{d q s}^{T} & \mathbf{i}_{d q r}^{T} & \mathbf{i}_{d q g}^{T}
\end{array}\right] \\
& \mathbf{i}_{d q \bullet}^{T}=\left[\begin{array}{ll}
i_{d \bullet} & i_{q \bullet}
\end{array}\right] \quad \mathbf{v}_{d q \bullet}^{T}=\left[\begin{array}{ll}
v_{d \bullet} & v_{q \bullet}
\end{array}\right] \\
& L_{s}=L_{l s}+M \quad L_{r}=L_{l r}+M \\
& L_{r}^{*}=L_{r}+L_{1} \quad r_{r}^{*}=r_{r}+r_{1} \\
& L=L_{2}+L_{L} \quad r=r_{2}+L_{L} \\
& \omega=d \theta / d t \quad \omega_{r}=d \theta_{r} / d t \\
& \omega_{\text {rel }}=\omega-\omega_{r} \quad M=\frac{3}{2} L_{m s} \\
& \mathbf{J}_{2}=\left[\begin{array}{cc}
0 & -1 \\
1 & 0
\end{array}\right]
\end{aligned}
$$

Furthermore, it is possible to rewrite the stator voltage in a more proper form. Combining with expressions (5) yields:

$$
\begin{aligned}
& \mathbf{v}_{d q s}=\mathbf{C} \mathbf{i}+\mathbf{D}_{g} \mathbf{v}_{d q g}+\mathbf{D}_{r} \mathbf{v}_{d q r} \\
& \mathbf{C}=\mathbf{L}_{S M 0} \mathbf{A}+\left(\mathbf{R}_{S 00}+\mathbf{X}_{S M 0}\right) \\
& \mathbf{D}_{g}=\mathbf{L}_{S M 0} \mathbf{B}_{g} \\
& \mathbf{D}_{r M 0}=\left[\begin{array}{lll}
L_{s} \mathbf{I}_{2} & M \mathbf{L}_{2 M 0} & \mathbf{0}_{2}
\end{array}\right] \\
& \mathbf{R}_{S 00}=\left[\begin{array}{lll}
r_{s} \mathbf{I}_{2} & \mathbf{0}_{2} & \mathbf{0}_{2}
\end{array}\right] \\
& \mathbf{X}_{S M 0}=\left[\begin{array}{lll}
\omega L_{s} \mathbf{J}_{2} & \omega M \mathbf{J}_{2} & \mathbf{0}_{2}
\end{array}\right]
\end{aligned}
$$

\section{Controllers design}

In a stand-alone system, it is necessary to regulate both the amplitude $V_{s}$ and the frequency $f_{e}$ of the generated stator voltage. This is associated with the following control objectives:

$$
\lim _{t \rightarrow \infty}\left(V_{s}^{*}-V_{s}\right)=0 \text { and } \lim _{t \rightarrow \infty}\left(f_{e}^{*}-f_{e}\right)=0
$$

where: $V_{s}^{*}$ y $f_{e}^{*}$ are the desired stator voltage amplitude and frequency, respectively.
The controllers design has been performed by following the same procedure used by Utkin and collaborators to design a controller for the squirrelcage induction motor (SCIM) in [9]-[10]. The main differences are: (i) The SCIM is fed and controlled from the stator, while the DFIG is fed both from stator and rotor, and it is controlled from the last one, and (ii) Utkin et. al consider a stationary reference frame in their design, while in this work an arbitrary reference frame is assumed. Moreover, this implies that actually a controller family is obtained, where each member is associated to a particular reference frame. The controller design procedure is described in the following paragraphs.

Consider the system in (5) and the output given in (6). Suppose the surfaces (8) or (9) are defined to satisfy the control objectives (7):

$$
\begin{aligned}
& \mathbf{s}_{1,2}=\mathbf{v}_{d q s}^{*}-\mathbf{v}_{d q s} \\
& \mathbf{s}_{1,2}=\int_{0}^{t}\left(\mathbf{v}_{d q s}^{*}-\mathbf{v}_{d q s}\right) d t
\end{aligned}
$$

where: $\mathbf{v}_{d q s}^{*}$ is the desired stator voltage vector, which implicitly contains the desired amplitude and frequency.

The surfaces defined in (8) have a common form directly related with control objectives (7), while the surfaces in (9) have been defined because the operations associated with the controller design will be simpler than the corresponding to surfaces (8).

Although Utkin et al. did not propose a general method for controlling electric machines, by analyzing their work following procedure has been defined:

(I) System motion on subspace $\mathbf{s}_{1,2}$ is found using (8),

(6), (5) and the transformation given in Table 1:

$$
\begin{aligned}
\dot{\mathbf{S}}_{1,2} & =\mathbf{F}_{1,2}-\mathbf{D} \cdot \mathbf{v}_{123 r} \\
\mathbf{F}_{1,2} & =p \mathbf{v}_{d q s}^{*}-p \mathbf{C} \cdot \mathbf{i}-\mathbf{D}_{r} \cdot p \mathbf{v}_{d q r}-\ldots \\
& \ldots-p\left(\mathbf{D}_{g} \mathbf{v}_{d q g}\right)-\mathbf{C A} \cdot \mathbf{i}-\mathbf{C} \mathbf{B}_{g} \mathbf{v}_{d q g} \\
\mathbf{D}= & \mathbf{D}_{1,2} \cdot \mathbf{A}_{d q}^{\alpha \beta} \cdot \mathbf{A}_{\alpha \beta}^{a b c} \cdot \mathbf{A}_{a b c}^{123} \\
& =\mathbf{D}_{1,2} \cdot \mathbf{A}_{d q}^{\alpha \beta} \cdot \mathbf{A}_{\alpha \beta}^{a b c} \\
\mathbf{D}_{1,2} & =p \mathbf{D}_{r}+\mathbf{C} \mathbf{B}_{r}
\end{aligned}
$$

where: $p$ is the differential operator $d / d t$.

By considering surfaces (9) it can be obtained:

$$
\begin{aligned}
& \mathbf{F}_{1,2}=\mathbf{v}_{d q s}^{*}-\mathbf{C} \cdot \mathbf{i}-\mathbf{D}_{g} \mathbf{v}_{d q g} \\
& \mathbf{D}_{1,2}=\mathbf{D}_{r}
\end{aligned}
$$


(II) To verify sliding regime can be established (system moving on $\mathbf{s}_{1,2}=\mathbf{0}$ ) and to obtain a control vector able to enforce it:

a. a Lyapunov candidate function (11) is defined:

$v=1 / 2 \mathbf{s}_{1,2}^{T} \cdot \mathbf{Q} \cdot \mathbf{s}_{1,2} \geq 0$

$\mathbf{Q}=\left[\mathbf{D}_{1,2} \cdot \mathbf{D}_{1,2}^{T}\right]^{-1}$

b. it is necessary that the function $v$ possesses a decreasing behavior. So, its time derivative is found by using (11) and (10):

$$
\dot{v}=\mathbf{s}_{1,2}^{T} \cdot \mathbf{Q} \cdot\left(\mathbf{F}_{1,2}-\mathbf{D} \cdot \mathbf{v}_{123 C}\right)+\frac{1}{2} \mathbf{s}_{1,2}^{T} \cdot \dot{\mathbf{Q}} \cdot \mathbf{s}_{1,2}
$$

c. the surfaces transformation (13) is defined as:

$$
\begin{aligned}
& \mathbf{s}^{*}=\mathbf{D}^{+} \mathbf{s}_{1,2}=\left[\begin{array}{lll}
s_{1}^{*} & s_{2}^{*} & s_{3}^{*}
\end{array}\right]^{T} \\
& \mathbf{D}^{+}=\mathbf{D}^{T}\left[\mathbf{D} \cdot \mathbf{D}^{T}\right]^{-1}=\frac{3}{2} \mathbf{D}^{T} \mathbf{Q}
\end{aligned}
$$

d. the next control vector is proposed:

$$
\begin{aligned}
& \mathbf{v}_{123 r}=\frac{1}{2} V_{0} \operatorname{sign}\left(\mathbf{s}^{*}\right) \\
& \operatorname{sign}\left(\mathbf{s}^{*}\right)=\left[\begin{array}{lll}
\operatorname{sign}\left(s_{1}^{*}\right) & \operatorname{sign}\left(s_{2}^{*}\right) & \operatorname{sign}\left(s_{3}^{*}\right)
\end{array}\right]^{T}
\end{aligned}
$$

(III) Expression (12) can be rewritten by substituting (13)-(14):

$$
\begin{gathered}
\dot{v}=\left(\mathbf{s}^{*}\right)^{T} \mathbf{D}^{T} \cdot \mathbf{Q} \cdot \mathbf{F}_{1,2}+\frac{1}{2} \mathbf{s}^{T} \cdot \dot{\mathbf{Q}} \cdot \mathbf{s}-\ldots \\
\ldots-\left(\frac{2}{3}\right)^{2}\left(\frac{1}{2} V_{0}\right)\left(2\left|s_{l}^{*}\right|+\left|s_{m}^{*}\right|+\left|s_{n}^{*}\right|\right)
\end{gathered}
$$

where: $l \neq m \neq n$, and $l, m, n \in\{1,2,3\}$

From (15), it can be deduced that there is a dc-link voltage $V_{0}$ high enough such that $\dot{v}<0$ for all possible combinations of $l, m$ and $n$, provided that $\left\|\mathbf{s}^{*}\right\| \neq 0$ and regardless the possible variation of disturbances contained in the first two terms of $\dot{v}$. This implies that sliding regime can be reached in finite time by directly switching the controls $v_{1 r}, v_{2 r}$ and $v_{3 r}$ given in (14).

The controller implementation must consider next steps: (i) determine sliding surfaces (8) or (9) from measurements; (ii) carry out sliding surfaces transformation by using (13); (iii) obtain control vector with (14); and (iv) determine gate pulses with proper expression in set (2).

Two facts must be highlighted: (A) expression (13) implicitly considers reference frame transformation. So, its final form depends on the chosen orientation; (B) the first two terms of (15) depend on system parameters contained in matrix $\mathbf{Q}$ and in the reference frame orientation. In fact, and considering fixed parameters, used orientation can affect the conditions for sliding regime establishment. In accordance, there are reference frames where it is more "easy" to enforce sliding regime. Consequently, the dc-link voltage can be smaller when these reference frames are considered.

\section{Simulation results}

In simulations it has been considered a $50 \mathrm{hp}$ DFIG, a $200 \mathrm{hp} \mathrm{dc}$ motor and a three-phase RL load, whose parameters are: (i) $r_{s}=0.087 \Omega, L_{l s}=L_{l r}{ }^{\prime}=0.8 \mathrm{e}-3$ $\mathrm{H}, r_{r}{ }^{\prime}=0.228 \Omega, L_{m}=34.7 \mathrm{e}-3 \mathrm{H}, \mathrm{P}=2$, (ii) $r_{f}=12 \Omega, L_{f}=9$ $\mathrm{H}, r_{a}=0.012 \Omega, L_{a}=35 \mathrm{e}-5 \mathrm{H}, L_{a f}=0.18 \mathrm{H}, J_{m}=30 \mathrm{Kg} \cdot \mathrm{m}^{2}$, and (iii) $r_{L}=10 \Omega$ y $L_{L}=0.015 \mathrm{H}$, respectively. In addition, it has been supposed an initial dc motor speed of $41 \mathrm{rad} / \mathrm{s}$ and a desired one of $41.9 \mathrm{rad} / \mathrm{s}$. Also, simulations suppose the dc motor is mechanically coupled to the DFIG through a rigid shaft without any friction and an ideal gearbox of ratio 4. Moreover, the dc-link voltage is considered to be initially equal to its desired value. This voltage is regulated by PIcontrollers through the FEC. Finally, a filtered stator voltage, using a second order band-pass filter, will be presented.

For the controller designed with surfaces (8) matrix $\mathbf{D}_{1,2}$ is:

$$
\begin{aligned}
\mathbf{D}_{1,2}= & \frac{1}{d^{2}}\left[\begin{array}{cc}
a_{1} & a_{2} \\
-a_{2} & a_{1}
\end{array}\right] \\
a_{1}= & M\left[L_{2} L_{L}\left(r_{s} L L_{r}^{*}+r_{r}^{*} L L_{s}+r_{r}^{*} L_{2} L_{L}\right)-\sigma\left(r_{L} L_{2}^{2}+r_{2} L_{L}^{2}\right)\right] \\
a_{2}= & M L_{2} L_{L} d \omega_{r} \quad d=\sigma L+L_{2} L_{L} L_{r}^{*} \\
\sigma= & \left(L_{s} L_{r}^{*}-M^{2}\right) \\
& \text { This controller has been simulated in }
\end{aligned}
$$
Simulink/MATLAB ${ }^{\mathbb{B}}$ in a stationary reference frame and in a stator-voltage-oriented one. In the last one, the dc-link voltage must be too high in order to enforce the sliding regime. This makes that approach to be practically unfeasible. Better results have been obtained in a stationary reference frame, since (15) imposes less severe restrictions on the dc-link voltage. Figure 3 shows some corresponding simulation results. Note that sliding regime is enforced in one half of the electric signal cycle. Desired amplitude and frequency are $V_{s}^{*}=220 \sqrt{2} \mathrm{~V}$ and $f_{e}^{*}=60 \mathrm{~Hz}$, respectively, also a PI-controlled dc-link voltage of $600 \mathrm{~V}$ has been used.

For the controller designed with surfaces (9) matrix $\mathbf{D}_{1,2}$ is:

$$
\mathbf{D}_{1,2}=\frac{M L_{L} L_{2}}{d} \mathbf{I}_{2}
$$

This controller has been simulated in a stationary reference frame and in a stator-voltage-oriented one. 
In the last one better results have been obtained, in contrast with the previous controller. However, the dclink voltage has to be relatively higher in order to obtain acceptable results, which can be considered practically unfeasible. Figure 4 shows some corresponding simulation results. Note that sliding regime is enforced in almost one half of the electric signal cycle. A dc-link voltage of $1100 \mathrm{~V}$ has been used.
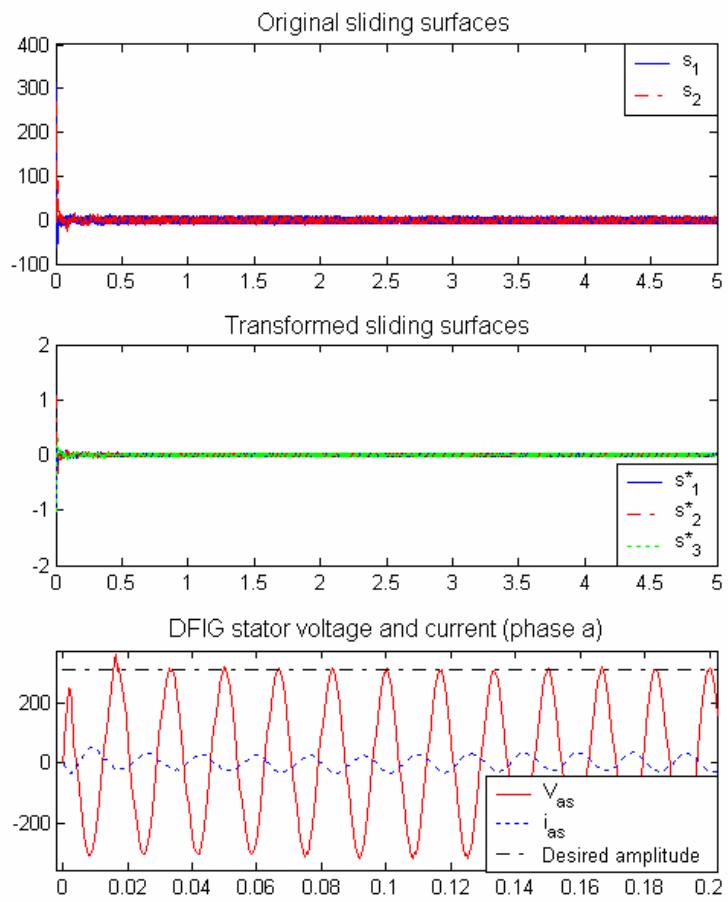

Figure 3. First controller simulation results.

\section{Conclusions}

This paper presents the design of two SMC controller families for the voltage generated by a DFIG that supplies a RL load in a stand-alone WECS. The design has been performed following the same procedure used by Utkin et. al in speed/torque squirrelcage induction motor control. Preliminary simulation results have been presented, which show good behavior. However, it is still necessary to verify some items, like the assessment of controller robustness and several practical implementation issues.

\section{References}

[1] S. Müller, M. Deicke, and R.W. De Doncker: "Doubly fed induction generator systems", IEEE Industry Applications Magazine, May-June, 2002, pp. 26-33.

[2] S. Tnani, S. Diop, S.R. Jones, and A. Berthon: "Novel Control Strategy of Double-fed Induction Machines", EPE'95, Sevilla, 6 pp.
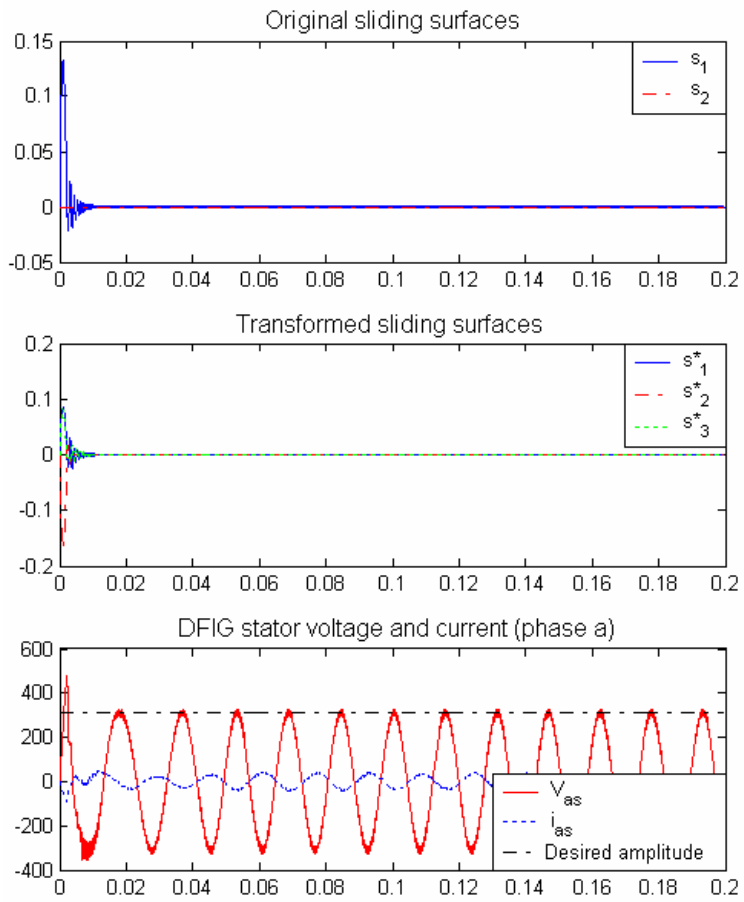

Figure 4. Second controller simulation results.

[3] A. Mebarki, and R.T. Lipczynski: "A Novel Variable Speed Constant Frequency Generation System with Voltage Regulation", EPE'95, Sevilla, 7 pp.

[4] R.S. Peña, G.M. Asher, J.C. Clare, and R. Cardenas: "A constant frequency constant voltage variable speed stand alone wound rotor induction generator", Opportunities and Advances in International Power Generation, Conference Publication No. 419, March 1996, pp. 111114.

[5] R. Peña, J.C. Clare, and G.M. Asher: "A doubly fed induction generator using back-to-back PWM converters supplying an isolated load from a variable speed wind turbine", IEE Proc.-Electr. Power Appl., Vol. 143, No. 5, September 1996, pp. 380-387.

[6] R.S. Peña, R.J. Cardenas, G.M. Asher, and J.C. Clare: "Vector controlled induction machines for stand-alone wind energy applications", Record of the 2000 IEEE Industry Applications Conference, Vol. 3 , 8-12 Oct. 2000, pp. $1409-1415$.

[7] Paul C. Krause: Analysis of Electric Machinery, Mc Graw Hill Company, Singapore, 1987.

[8] V.F. Pires, and J.F. Silva: "Teaching Nonlinear Modeling, Simulation, and Control of Electronic Power Converters Using MATLAB/SIMULINK", IEEE Transactions on Education, Vol. 45, No. 3, August 2002, pp. 253-261.

[9] V.I. Utkin, J. Güldner, and J. Shi: Sliding Mode Control in Electromechanical Systems, CRC Press, ISBN. 07484-0116-4, 1999.

[10] V.I. Utkin: "Sliding mode control design principles and applications to electric drives", IEEE Transactions on Industrial Electronics, Vol. 40, No. 1, Feb. 1993, pp. 23 -36 . 